\title{
Camless Engine Control for a Robust Unthrottled Operation
}

\author{
M. S. Ashhab \\ University of California, Santa Barbara
}

\author{
A. G. Stefanopoulou, J. A. Cook, and M. B. Levin \\ Ford Research Lab.
}

\section{ABSTRACT}

Substantial improvements in engine fuel efficiency, torque and reduction of emissions are available with camless actuation capable of continuous control of engine valve lift, duration and timing. A phenomenological model has been developed for an unthrottled operation that is key to efficiency gain. An adaptive nonlinear controller has been designed to coordinate intake valve lift and duration by using high sampling rate intake manifold pressure and flow sensors. The driver torque demand is satisfied, while pumping losses are minimized. Simulation results for a 4 cylinder $2.0 \mathrm{~L}$ engine demonstrate event-to-event tracking and cylinder-to-cylinder balancing. The controller corrects for variations in effective flow areas (e.g. valve deposits), induction ram effects, and temperature.

\section{INTRODUCTION}

The majority of today's automotive engines use mechanical valvetrains to operate the intake and exhaust valves. The valve motion is timed to the crankshaft rotation through mechanical links between the crankshaft and the camshaft and between the camshaft and the individual valves. This type of valve actuation has been proven efficient and dependable. However, the lack of flexibility of camshaft-based valvetrains to vary timing, duration and lift of intake valves, is one of the major causes for significantly lower fuel efficiency of spark-ignited (SI) engines as compared to their diesel counterparts. The key difference is that for SI engines the non-variable valve events require throttling of intake air flow upstream of the intake manifold to satisfy the driver torque demand below the maximum torque value. The throttling significantly reduces engine efficiency by introducing pumping losses. Thus, one way to improve fuel economy of SI engines is to run with wide open throttle at all speed/load conditions, and to control the cylinder air flow by optimizing the motion of the intake valves with an electrohydraulic camless valvetrain $[1,2]$ as shown in Figure 1 . Recent advances in camless valve actuation hardware and real-time computing are making possible the application of fully controlled valve events that can improve the gas exchange process.

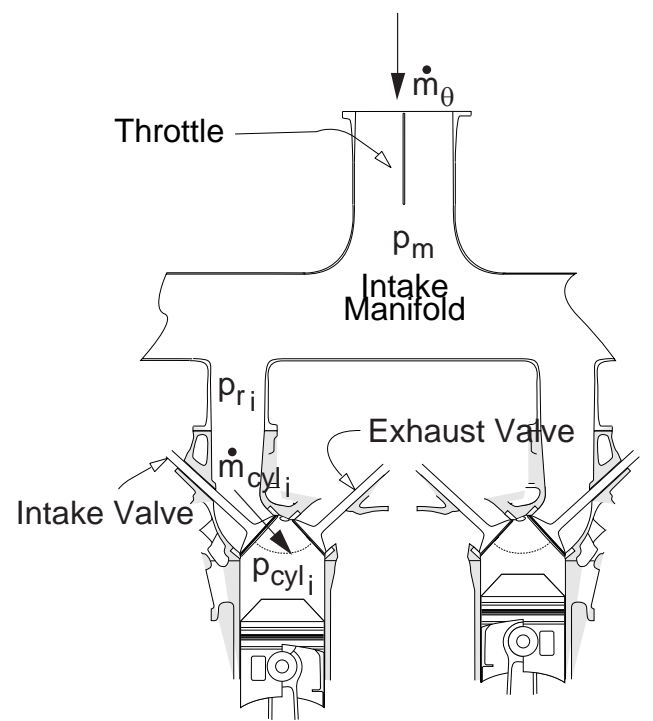

Figure 1: Schematic representation of the unthrottled engine.

The camless engine controller has to accomplish two main tasks: first, it must have sufficiently fast response to rapid changes in driver torque demand; and, secondly, it must assure robust operation. It means that, given a fast and reliable camless actuation system, the engine controller must rapidly coordinate the intake valve lift (IVL) and intake valve duration (IVD) to achieve the required torque response, while providing correction for slowly varying parameters such as aging and manufacturing variability of the engine and valvetrain components. Modern control design techniques can correct the engine operation in response to slowly changing actuator or engine characteris- 
tics. Thus, efforts to improve camless valvetrains have to be combined with a systematic study of the engine controller and the related engine sensor requirements.

The paper describes a design of a real-time controller that only uses Mass Air Flow (MAF) and Manifold Absolute Pressure (MAP) sensors. An indirect adaptive control design is based on a phenomenological model for the individual cylinder breathing dynamics. The engine model developed by Moraal et al. in [3] is coupled with a simplified model of an electrohydraulic camless valvetrain mechanism developed by Schechter and Levin in [4].

The paper is organized as follows. First, a controloriented Camless Engine Model is described. The effects of the actuator characteristics on the cylinder air charge and pumping losses are investigated in the Sensitivity Analysis section. Specifically, it is shown how the IVO, IVC, IVL, and IVD affect engine cylinder air charge and pumping losses. Based on this analysis and recent work [5], IVO can be set to zero at all loads for medium engine speeds. To simplify the estimation task the scope of this paper has been limited to a four cylinder engine with no cylinder overlap, i.e. the IVD has been limited to $180 \mathrm{deg}$ crankshaft. The adaptive controller design is described in the Control Design section. Finally, the controller adaptation and balancing capabilities are presented in the Closed Loop Simulation Results section.

\section{NOMENCLATURE}

The subscript $i$ denotes the cylinder. $i=1,2, \ldots, n$.

$\begin{aligned} A_{r} & =\text { runner cross sectional area } \\ B & =\text { cylinder bore } \\ C A C & =\text { cylinder air charge } \\ I V C & =\text { intake valve closing timing } \\ I V D & =\text { intake valve duration } \\ I V L & =\text { intake valve maximum lift } \\ I V O & =\text { intake valve opening } \\ I V P & =\text { intake valve profile } \\ M_{c} & =\text { air mass in the cylinder } \\ \dot{m}_{c} & =\text { mass air flow rate through the intake port } \\ \dot{m}_{\phi} & =\text { mass air flow rate through the throttle } \\ N & =\text { engine speed } \\ p_{o} & =\text { ambient pressure: } 1 \text { bar } \\ p_{c} & =\text { cylinder pressure } \\ p_{m} & =\text { intake manifold pressure } \\ p_{r} & =\text { runner pressure at the intake port } \\ R & =\text { specific gas constant: } 287 \frac{J}{K g . K} \\ T & =\text { air temperature } \\ V_{c} & =\text { cylinder volume } \\ V_{c l} & =\text { cylinder clearance volume } \\ V_{d} & =\text { intake manifold volume } \\ V_{m} & =\end{aligned}$

$$
\begin{aligned}
V_{r} & =\text { intake runner volume } \\
v_{p} & =\text { piston velocity } \\
W & =\text { pumping losses } \\
\phi & =\text { throttle angle } \\
\theta & =\text { crank angle } \\
\rho & =\text { constant that depends on runner geometry } \\
\omega_{h} & =\text { Helmholtz resonator natural frequency } \\
\xi_{h} & =\text { Helmholtz resonator damping ratio } \\
s_{r}, s_{c}, & \text { and } s_{s}, d_{s}, \lambda \\
& =\text { intake valve profile parameters }
\end{aligned}
$$

\section{CAMLESS ENGINE MODEL}

In this section we describe the phenomenological model of the individual cylinder breathing process that is appropriate for real-time control of unthrottled camless engines. This model fills the gap between the analytical thermodynamic engine models $[6,7]$ and the steady-state or mean-value engine models $[8,9]$ that are currently used in the field of engine design and control. Controller development for engines equipped with camless valvetrains requires an accurate yet simple model of the cylinder-tocylinder gas exchange process. Earlier work by Moraal et al. in [3] describes the induction process in the individual cylinders of a conventional engine and derives a model-based observer for cylinder-to-cylinder air-to-fuel ratio control. In this section we modify this model to incorporate the individual intake valve control necessary for a camless engine.

CYLINDER BREATHING DYNAMICS - The intake manifold and runners, and cylinders shown in Figure 1 can be represented as finite volumes based on the "Filling and Emptying Methods" of plenum modeling described in [10]. The dynamic equations that characterize the air filling dynamics are based on the principles of conservation of mass, conservation of energy, and the ideal gas law.

The intake manifold filling dynamics can be described by the following first order differential equation that relates the rate of change of the manifold pressure, $p_{m}$, to the mass air flow rates into and out of the manifold $\left(\dot{m}_{\theta}\right.$ and $\dot{m}_{c}=\sum_{i=1}^{n} \dot{m}_{c_{i}}$, respectively)

$$
\frac{d p_{m}}{d t}=\frac{R T}{V_{m}}\left[\dot{m}_{\phi}-\sum_{i=1}^{n} \dot{m}_{c_{i}}\right],
$$

where, $R=287 \frac{\mathrm{J}}{\mathrm{kg} \cdot \mathrm{K}}$ the specific gas constant, $T=293$ $K$ the nominal manifold temperature, and $V_{m}=0.001 \mathrm{~m}^{3}$ the manifold volume.

The rate change of the cylinder pressure, $p_{c_{i}}$, is a function of the mass air flow rate into the cylinder, $\dot{m}_{c_{i}}$, and the rate of change of the cylinder volume, $\dot{V}_{c_{i}}$,

$$
\frac{d p_{c_{i}}}{d t}=\frac{1}{V_{c_{i}}}\left[R T \dot{m}_{c_{i}}-\dot{V}_{c_{i}} p_{c_{i}}\right],
$$

where, the subscript $i=1,2, \ldots, n$ denotes the cylinder. The crank angle and cylinder volume can be expressed as 
functions of time:

$$
\begin{aligned}
\theta & =\left(\frac{N}{60} 360 \cdot t\right) \bmod \left(720^{\circ}\right) \text { and } \\
V_{c_{i}}(\theta) & =\frac{V_{d}}{2}(1-\cos \theta)+V_{c l},
\end{aligned}
$$

where, $V_{d}=4 \times 10^{-4} \mathrm{~m}^{3}$ is the cylinder displaced volume, and $V_{c l}=4 \times 10^{-5} \mathrm{~m}^{3}$ is the cylinder clearance volume.

A quasi-steady model of flow through an orifice is used to derive the mass air flow through the throttle body and the intake valve. The quasi-steady relation of the air flow through a valve opening is based on the assumptions of one-dimensional, steady, compressible flow of an ideal gas [11]. An approximation of the flow through an orifice, $\dot{m}_{\phi}$, is calculated based on the effective flow area, $A(\phi)$, the downstream and the upstream pressures $\left(p_{d}\right.$, and $p_{u}$, respectively):

$$
\begin{aligned}
& \dot{m}_{\phi} \quad=A(\phi) d\left(p_{d}, p_{u}\right) \text {, where } \\
& d\left(p_{d}, p_{u}\right)=\left\{\begin{array}{lll}
1 & & \frac{p_{d}}{p_{u}}<0.5 \\
2 \sqrt{\frac{p_{d}}{p_{u}}-\left(\frac{p_{d}}{p_{u}}\right)^{2}} & \text { if } \quad & 0.5 \leq \frac{p_{d}}{p_{u}}<1 \\
-d\left(p_{u}, p_{d}\right) & & \frac{p_{d}}{p_{u}}>1
\end{array}\right.
\end{aligned}
$$

Based on the above equations, we derive the flow through the throttle body, $\dot{m}_{\phi}$, and the intake valve, $\dot{m}_{c_{i}}$, as follows:

$$
\begin{aligned}
& \dot{m}_{\phi}=A_{\phi}(\phi) d\left(p_{m}, p_{o}\right), \text { and } \\
& \dot{m}_{c_{i}}=A_{v}\left(I V P_{i}\right) d\left(p_{c_{i}}, p_{r_{i}}\right)
\end{aligned}
$$

where, $p_{o}=1$ bar denotes the ambient pressure, $A_{\phi}$ is the effective throttle body area as computed in [3], $A_{v_{i}}=$ $\frac{0.14}{8} I V P_{i}$ is the valve effective area (see [10]), and $p_{r_{i}}$ is the runner pressure. The pressure in the runner at the intake port, $p_{r_{i}}$, is computed by the following equation:

$$
p_{r_{i}}=\left(1+\frac{V_{r} \rho \dot{q_{i}}}{R T A_{r}}\right) p_{m}
$$

where, $V_{r}$ is the runner volume, $A_{r}$ is the runner cross sectional area, and $\rho$ is a calibration constant that depends on the geometry of the runners. The runner dynamics depends on the solution of the Helmholtz resonator, namely, the state $\dot{q}_{i}$ is found from the solution of the Helmholtz resonator equation:

$$
\begin{aligned}
& \ddot{q}_{i}+2 \xi_{h} \omega_{h} \dot{q}_{i}+\omega_{h}^{2} q_{i}=\frac{\pi B^{2}}{4 A_{r}} \omega_{h}^{2} v_{p_{i}} \\
& \dot{q}_{i}(0)=0 \\
& q_{i}(0)=0 .
\end{aligned}
$$

The damping ratio, $\xi_{h}$, and the natural frequency, $\omega_{h}$, of the Helmholtz resonator depend on the vehicle intake system characteristics. Furthermore, $B=0.0806 \mathrm{~mm}$ is the cylinder bore, and $v_{p_{i}}=\frac{2 \pi N}{120} S \sin \theta$ is the piston velocity, where, $S=0.088 \mathrm{~m}$ is the stroke.

INTAKE VALVE MOTION - Microprocessor controlled camless valvetrain actuation enables valve motion.
In this paper, we use a simplified model of the electrohydraulic camless valvetrain in [4] to represent the variable intake valve motion.

The intake valve profile, $I V P$, is controlled by the valve opening, $I V O$ in degrees after top dead center ( $A T D C$, zero degrees correspond to $T D \bar{C}$ ), the maximum valve lift, $I V L$ in $\mathrm{mm}$, and the valve duration, $I V D$ in degrees. The intake valve profile is shown in Figure 2. Using engine model simulation, it is shown that the oscillations observed at maximum lift have negligible effects on the cylinder air charge and pumping losses. For simplicity we model the intake valve profiles with a smooth exponential opening that results in equivalent engine behavior. We parameterize the motion by the slope of the opening, $s_{r}$, slope of the closing, $s_{c}$, slope and duration of the seating, $s_{s}$ and $d_{s}$, and $\lambda$ which determines how fast the valve motion approaches the maximum lift after the opening.

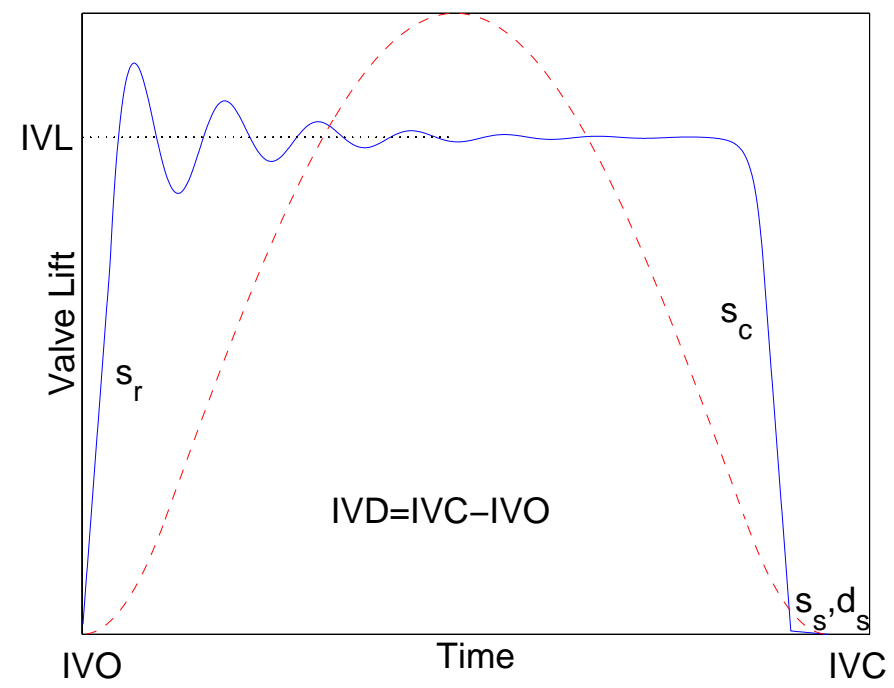

Figure 2: Camless (solid) and conventional (dashed) intake valve profiles at engine speed of 1500 RPM.

The variables $I V O, I V L$, and $I V D$ are the control signals and are chosen to achieve the demanded cylinder air charge while minimizing pumping losses. The constants $s_{r}$, $s_{c}, s_{s}$, and $d_{s}$ are fixed in the time domain. A coordinate transformation to crankangle domain results in different valve profiles for different engine speeds. The area defined by the intake valve profile, IVP, is significantly reduced at higher engine speeds as shown in Figure 3.

SIMULATION ISSUES - The model described in the previous section was coded in Matlab Simulink CACSD software. The Matlab stiff integration numerical algorithm was used to solve the nonlinear, stiff and highly coupled differential equations of the system. This integration scheme with relative tolerance equal to $10^{-6}$ and absolute tolerances equal to $10^{-9}$ reduced the numerical problems described in [12]. Numerical integration of the system of differential equations (1)-(2) is difficult due to the presence of singularity when the pressure ratio across one of the orifices in (8) is almost equal to one. In this case, the induction system exhibits fast and slow dynamics which manifest themselves as a stiff dynamical system [13]. 


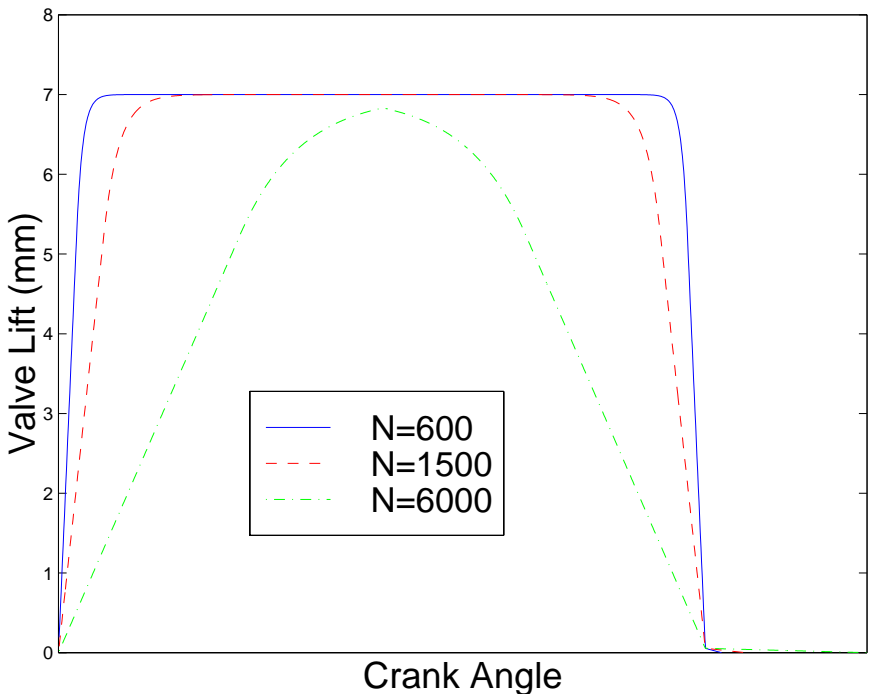

Figure 3: Intake valve profiles for different speeds.

To initialize the simulation, the manifold pressure is assumed to be equal to the ambient pressure, $p_{m}(0)=p_{o}$, since the throttle is wide open. The model does not take into account the overlap between the intake and exhaust valves $^{1}$ and describes only the intake event of the engine cycle. Therefore, we assume that the cylinder pressure when the intake valve opens, $p_{c_{i}}\left(I V O_{i}\right)$, is equal to the cylinder pressure at the end of the exhaust stroke. In turn, we assume that the cylinder pressure at the end of the exhaust stroke is equal to the exhaust backpressure, $p_{c_{i}}\left(I V O_{i}\right)=p_{c_{i}}\left(E V C_{i}\right)=1.1$ bar. Thus, each cylinder pressure is initialized at the beginning of every intake event by triggering the cylinder pressure integrator in the simulation model.

Figure 4 shows the simulation results. For the electrohydraulic intake valve profile shown in subplot 1 the pressures $p_{m}, p_{c_{i}}$ and $p_{r_{i}}$ (subplot 2), and the mass air flow rates $\dot{m}_{c_{i}}$ and $\dot{m}_{\phi}$ (subplot 3 ) are plotted against the crank angle $\theta$. The manifold pressure, $p_{m}$, stays close to the ambient pressure due to unthrottled operation. The downward piston motion causes the cylinder pressure, $p_{c_{i}}$ to drop from its initial value. As air flows from the runner to the cylinder, the cylinder pressure varies according to EQ (2). During closed intake valves, EQ (2) reduces to the following relation

$$
p_{c_{i}}=\frac{M_{c_{i}} R T}{V_{c_{i}}}
$$

where, $M_{c_{i}}$ is the air mass in the cylinder.

During unthrottled operation the rate of change of manifold pressure is very small, i.e., $\frac{d p_{m}}{d t} \approx 0$. Consequently, the mass air flow through the intake port and throttle are almost equal, see subplot 3 in Figure 4, where $\dot{m}_{\theta} \approx \sum_{i=1}^{n} \dot{m}_{c_{i}}$ from EQ (1). The mass air flow is negative (backflow through the intake valves and the throttle

\footnotetext{
${ }^{1}$ To avoid future confusion, we call "valve overlap" the overlap between the exhaust and the intake valve of the same cylinder. Accordingly, we call "cylinder overlap" the intake valve overlap of different cylinders.
}

body) when the intake valve opens, because the cylinder pressure is higher than the manifold pressure $\left(\frac{p_{c}}{p_{m}}>1\right.$ in EQ (8)). The downward piston motion creates a differential pressure between the cylinder and runners $\left(\frac{p_{c}}{p_{m}}<1\right.$ in EQ (8)), which causes the air to flow from the runner to the cylinder for the rest of the intake valve duration.
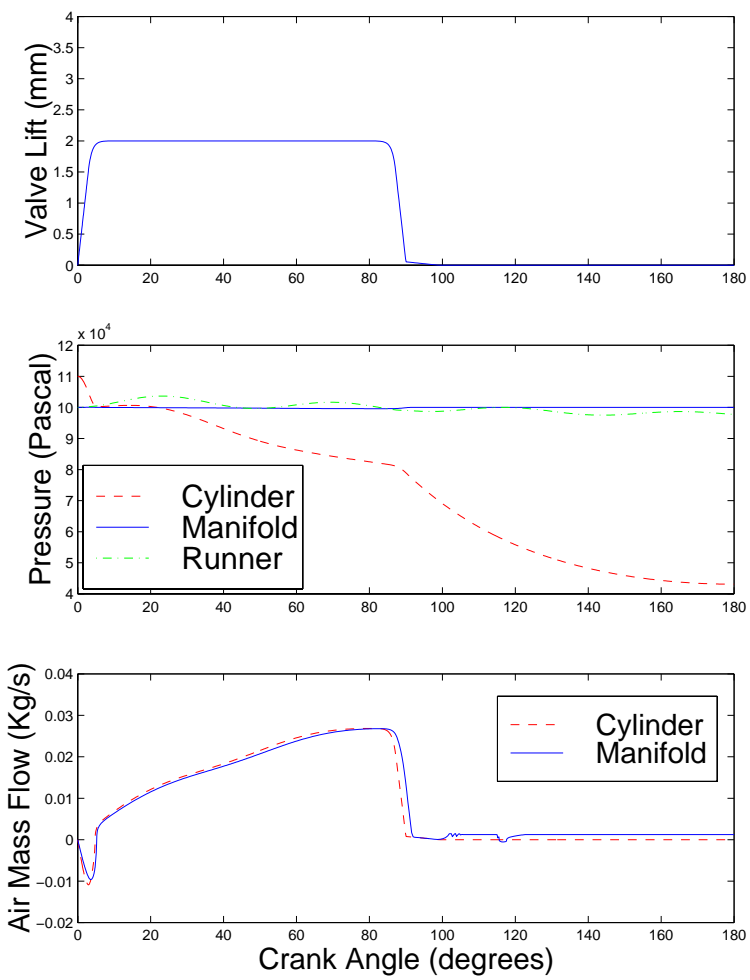

Figure 4: Engine breathing characteristics for $1500 \mathrm{rpm}$.

The cylinder air charge, $C A C_{a}$, is obtained by integrating the mass air flow through the intake port over the intake valve duration, $I V D$, i.e.,

$$
C A C_{a}=\int_{I V O}^{I V O+I V D} \dot{m}_{c_{i}} d t
$$

The resulting cylinder air charge in Figure 4 is equal to $1.74 \cdot 10^{-4} \mathrm{~kg}$ /event that corresponds to bmep=2.6 bar at an engine speed of 1500 RPM. The pumping loss, W, is calculated by the integral:

$$
W=\oint_{n e g}^{l o o p} p_{c_{i}} d V_{c_{i}} .
$$

We assume that the cylinder pressure was equal to the exhaust pressure for most part of the exhaust stroke, $p_{c_{i}}\left(E V C_{i}\right)=1.1$ bar. The pumping loss calculated for the unthrottled engine operation shown in Figure 4 that corresponds to 2.6 bmep is equal to $3.38 \mathrm{~J}$ at an engine speed of 1500 RPM. The same load (bmep=2.6 bar) at 1500 RPM is achieved with a conventional valvetrain by using throttle angle equal to $\phi=17.6$ degrees. The resulting pumping losses for the conventional throttled operation is $14.29 \mathrm{~J}$. Thus, unthrottled engine operation using camless valvetrain results in approximately $76 \%$ reduction in pumping losses which agrees with results by Miller et al. in [5]. The 
conventional and camless engine breathing process that is used to calculate the pumping loss is shown in Figure 5.

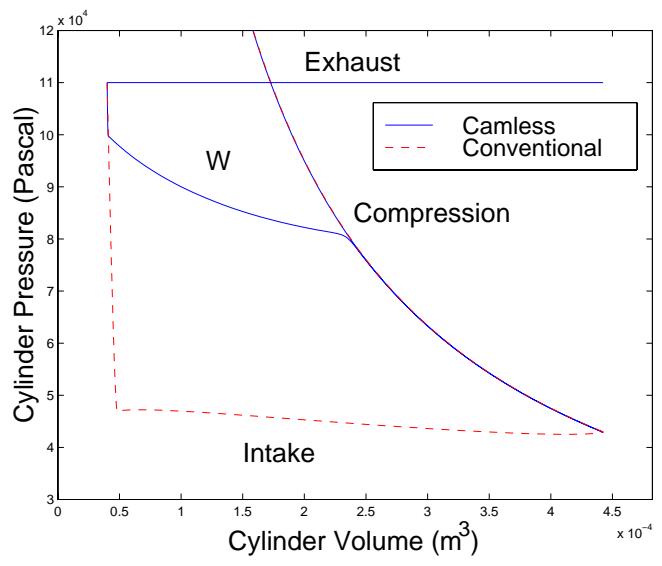

Figure 5: $\mathrm{P}-\mathrm{V}$ diagram showing pumping loss that corresponds to throttled and unthrottled engine operation for $C A C=1.74$. $10^{-4} \mathrm{~kg}$ /event and bmep $=2.6$ bar at engine speed of $1500 \mathrm{RPM}$.

\section{SENSITIVITY ANALYSIS}

In this section we perform sensitivity analysis of the control signals to the engine performance parameters, cylinder air charge, and pumping losses. This work is instrumental in coordinating IVO, IVL, and IVC to track torque demand and minimize pumping losses.

INTAKE VALVE OPENING - Figure 6 shows the effects of valve opening ( IVO) for constant $I V D$ and $I V L$ $\left(I V D=180^{\circ}, I V L=3.0 \mathrm{~mm}\right)$ to the cylinder breathing dynamics, namely, the manifold pressure (subplot 2), the cylinder pressure (subplot 3), and the mass air flow rate into the cylinder (subplot 4). The solid curve corresponds to $I V O=0^{\circ}$, dashed curve corresponds to $I V O=20^{\circ}$, and dot-dashed curve corresponds to $I V O=50^{\circ}$. Delaying the intake valve opening after the top dead center creates low pressure in the cylinder.

Figure 7 shows the cylinder air charge and pumping losses as functions of the intake valve opening, IVO, for constant intake valve duration, $I V D$, (first column of subplots) and constant closing timing, IVC (second column of subplots). Note that the sensitivity of the cylinder air charge and pumping losses to the intake valve opening is small around the top dead center. Moreover, the cylinder air charge decreases significantly for large values of $I V O$. Thus, there is no benefit from large increases in IVO. This result is in agreement with the work of Miller et al. in [5] where $I V O$ was set to zero at all loads and medium engine speed.

INTAKE VALVE DURATION - Figure 8 shows the effects of closing timing $(I V C)$ for constant $I V O$ and $I V L$ $\left(I V O=0^{\circ}, I V L=3.0 \mathrm{~mm}\right)$ to the cylinder breathing dynamics. We show the effects of IVC to the intake manifold pressure (subplot 2), cylinder pressure (subplot 3), and mass air flow (subplot 4). The solid line corresponds to $I V C=140^{\circ}$, dashed line corresponds to $I V C=180^{\circ}$, and dot-dashed line corresponds to $I V C=240^{\circ}$. The mani-
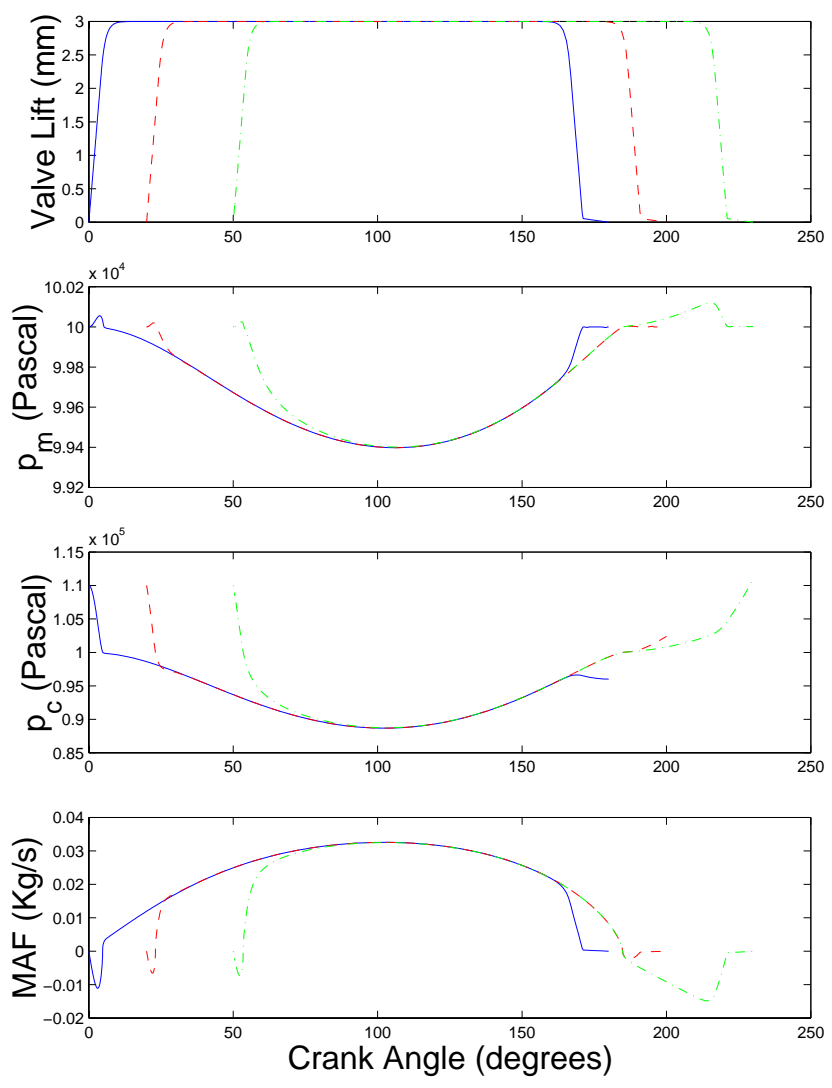

Figure 6: Effects of valve opening ( IVO $=0,20,50$ degrees) for constant $I V D$ and $I V L\left(I V D=180^{\circ}, I V L=3.0 \mathrm{~mm}\right)$ to the cylinder breathing dynamics at $1500 \mathrm{rpm}$ and $C A C=$ $4.529,4.559,3.425 \cdot 10^{-4} \mathrm{~kg} /$ event.
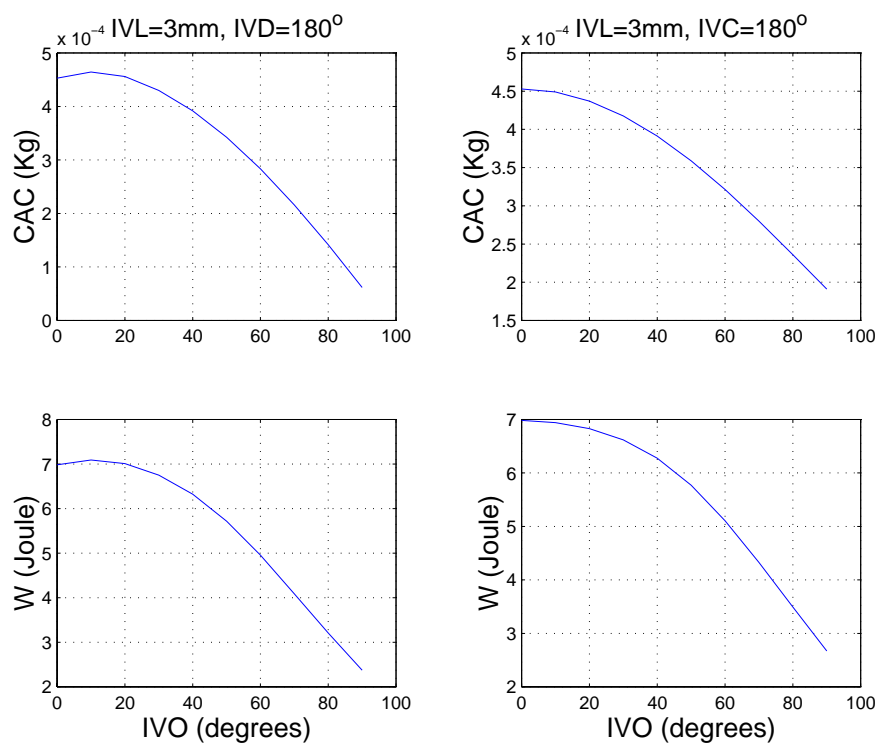

Figure 7: Cylinder air charge and pumping losses sensitivities to intake valve opening for fixed $I V D$ (first column) and fixed $I V C$ (second column) at $1500 \mathrm{rpm}$. 
fold pressure drops slightly below the atmospheric pressure while the intake valve is open, and goes back to the atmospheric pressure when the intake valve closes. Note that for late closing $\left(I V C>180^{\circ}\right)$, there is a cylinder overlap. In this case, the manifold pressure starts dropping late due to cylinder overlap. In the early closing case $\left(I V C<180^{\circ}\right)$, the cylinder pressure decreases after the intake valve closes because of the piston downward motion (expansion). The mass air flow through the intake valve $\left(\dot{m}_{c}\right)$ and throttle $\left(\dot{m}_{\phi}\right)$ are almost equal for early closing $\left(I V C<180^{\circ}\right)$, and closing at the fundamental event $\left(I V C=180^{\circ}\right)$. For late valve closing, the mass air flow through the intake valve $\left(\dot{m}_{c}\right)$ and throttle $\left(\dot{m}_{\phi}\right)$ are different at the beginning and end of the intake event due to the cylinder overlap.
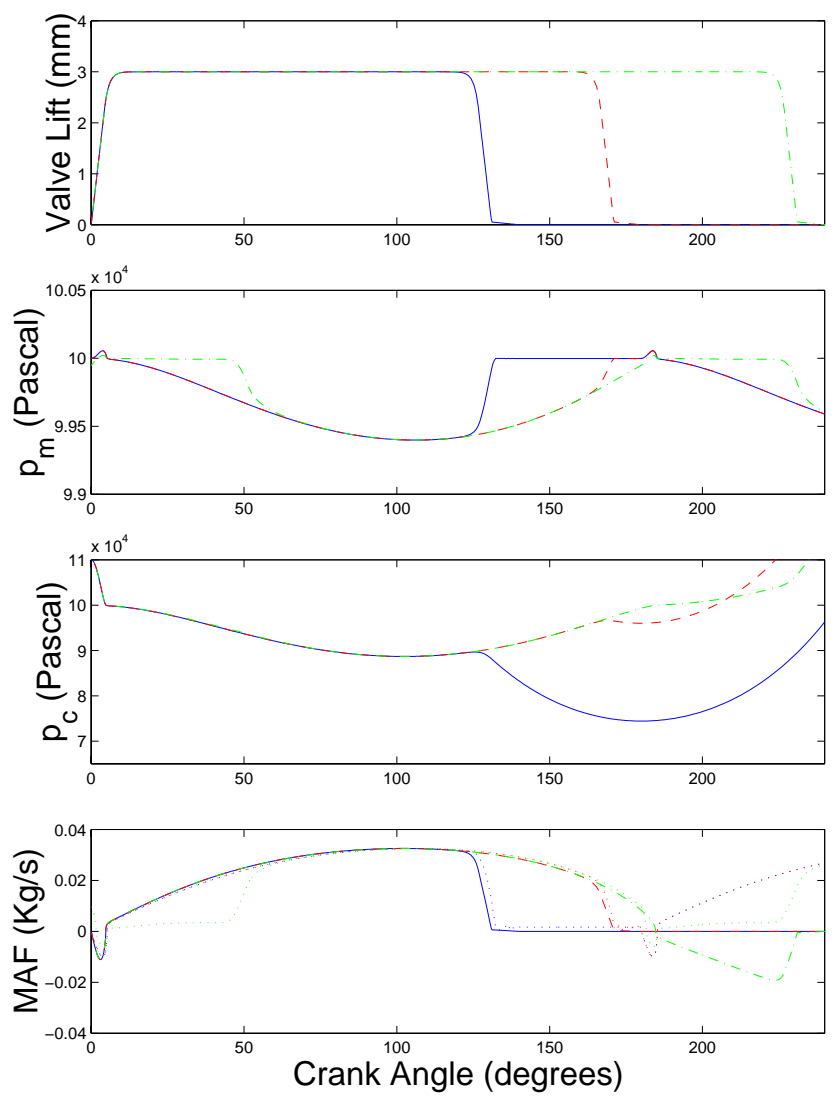

Figure 8: Engine breathing characteristics for different values of $I V D$ at $1500 \mathrm{rpm}$.

Figure 9 shows the cylinder air charge and pumping losses against the intake valve duration. The cylinder air charge is an almost linear function of the intake valve duration for all $I V D \leq 180$. Cylinder air charge continues to increase for $180<I V D<200$ because the intake valve duration (IVD, as defined earlier) includes the valve seating duration. For $I V D>200$ we have backwards flow from the cylinder to the runners due to the upward motion of the piston. Thus, for low and medium engine speeds we assume $I V D$ no greater than 180 degrees $A T D C$. This assumption again agrees with the results in [5].

INTAKE VALVE (MAXIMUM) LIFT - Figure 10 shows the effects of the intake valve (maximum) lift ( $I V L$ ) for constant IVO and IVD $\left(I V O=0^{\circ}, I V D=180^{\circ}\right)$ to the cylinder breathing dynamics. We show the effects
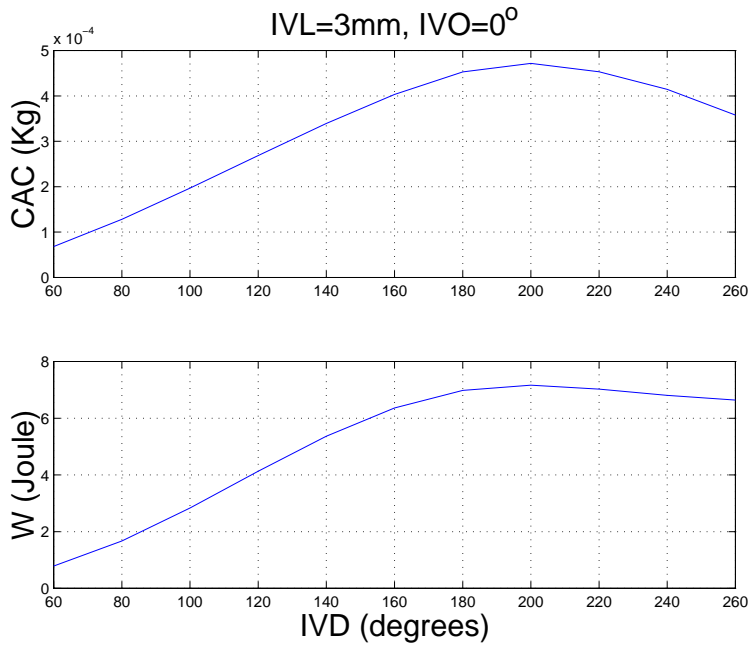

Figure 9: Cylinder air charge and pumping losses sensitivities to intake valve duration at $1500 \mathrm{rpm}$.

of IVL to the intake manifold pressure (subplot 2), cylinder pressure (subplot 3), and mass air flow (subplot 4). Solid line corresponds to $I V L=1 \mathrm{~mm}$, dashed line corresponds to $I V L=3 \mathrm{~mm}$, and dot-dashed line corresponds to $I V L=5 \mathrm{~mm}$. The important point is that the trapped cylinder air charge does not increase appreciably above 3 $\mathrm{mm}$ of lift. This occurs because the runner and cylinder pressures become almost equal which reduces the rate of mass air flow between the cylinder and the runners. Hence, in the saturation region, the cylinder air charge and pumping losses are not sensitive to the maximum intake valve lift (see Figure 11).
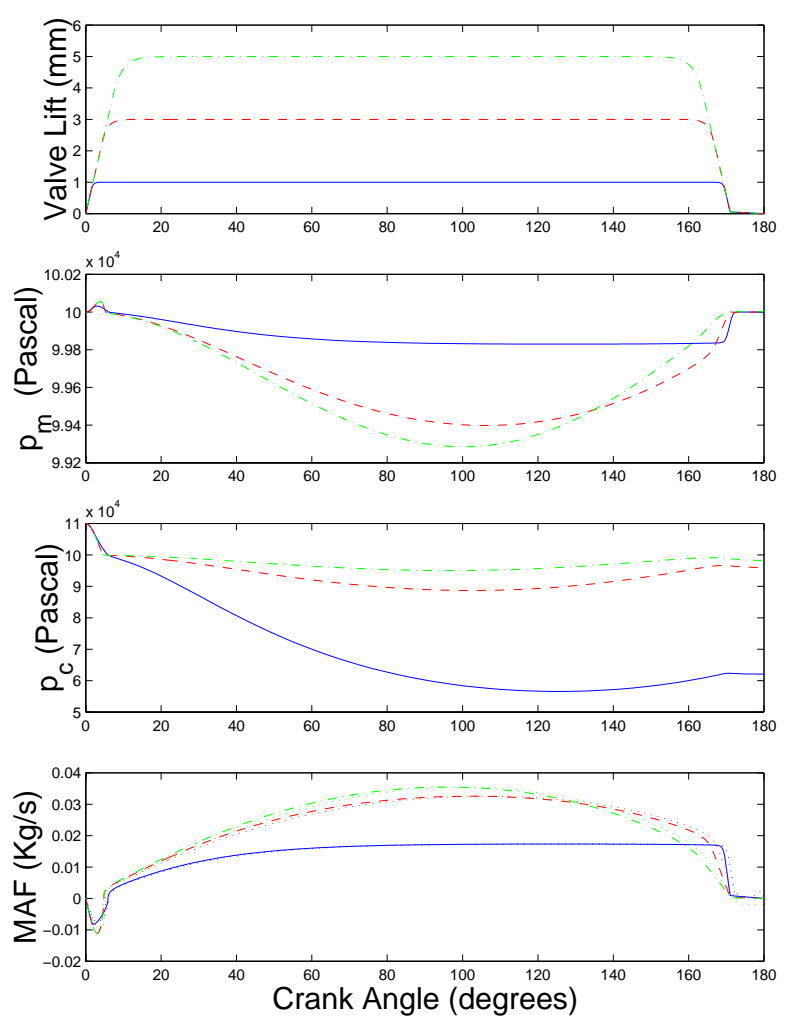

Figure 10: Engine breathing characteristics for different values of $I V L$ at $1500 \mathrm{rpm}$. 

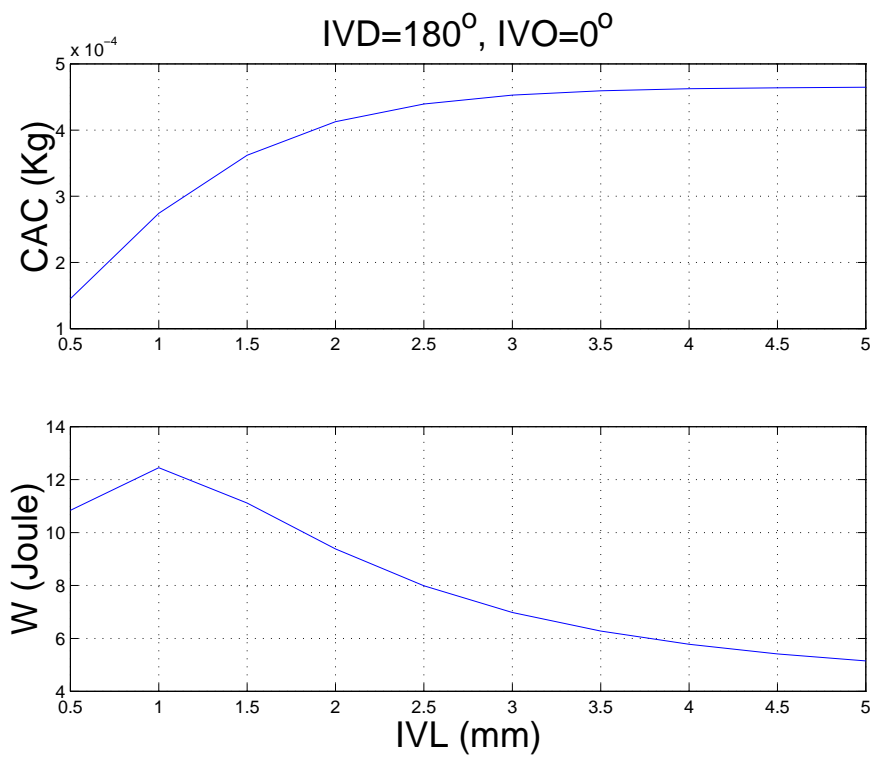

Figure 11: Cylinder air charge and pumping losses sensitivities to maximum intake valve lift $(1500 \mathrm{rpm})$.

\section{CONTROL DESIGN}

The engine controller schedules IVO, IVL and IVD to track the driver's torque demand during unthrottled operation. To simplify the controller design, we decompose the torque tracking problem into (i) tracking desired cylinder air charge, (ii) regulating air-to-fuel ratio, and (iii) scheduling spark timing. It is obvious that if we achieve tracking of the cylinder air charge and cylinder-to-cylinder balancing by intake valve motion control (problem (i)), problems (ii) and (iii) resemble the conventional air-to-fuel ratio and spark timing control. Thus, we concentrate on the individual cylinder air charge control for the camless unthrottled engine operation.

The desired cylinder air charge (Demand Map) that the engine controller must track can be specified by a nonlinear function of the pedal position and engine speed as shown in Figure 12. This function is usually developed by experienced drivers and calibrators and we assume that it is given. The main performance objectives for the engine controller are

- Fast speed of response to a cylinder air charge demand $\left(C A C_{d}\right)$.

- Robustness to parameter variations and modeling uncertainty.

Based on these performance objectives we design the indirect adaptive controller $[14,15]$. Fast speed of response is satisfied by the feedforward controller $\left(C\left(\xi_{c}\right)\right)$ that schedules IVO, IVL, and IVD in response to a cylinder air charge demand $\left(C A C_{d}\right)$. An engine controller architecture that is based only on feedback would limit the speed of response due to the inherent delays of the measurements. Robustness of the feedforward controller is ensured by the feedback controller that detects parameter variations and compensates for modeling errors. The feedback controller adapts the nonlinear feedforward scheme that is based on nominal engine characteristics to match the true engine characteristics. The controller consists of (i) a feedforward controller, (ii) controller parameter estimator, and (iii) adaptation rule as shown in Figure 12.

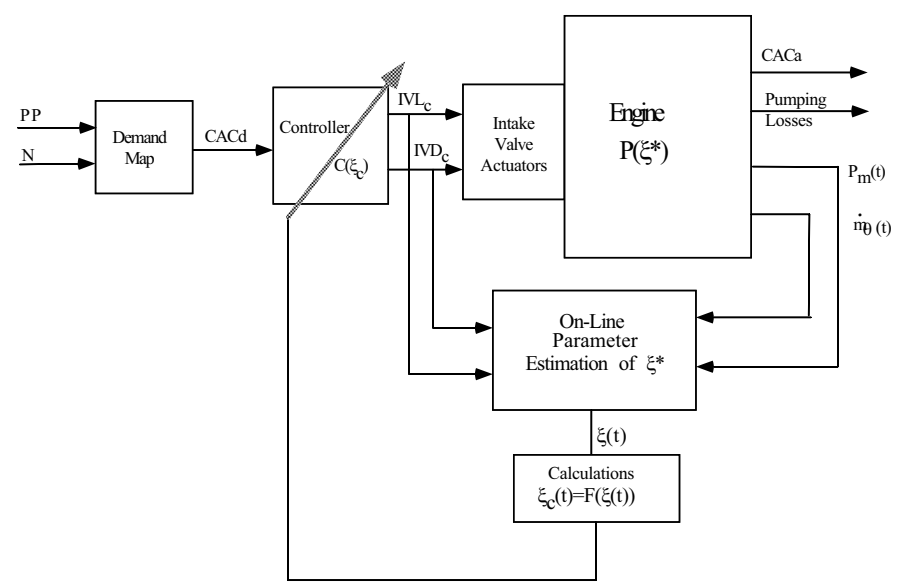

Figure 12: Block diagram of the camless engine control scheme.

FEEDFORWARD CONTROLLER - Based on the sensitivity analysis, the intake valve opening, IVO, is scheduled to zero independently of the cylinder air charge demand, $C A C_{d}$. The feedforward controller calculates the necessary $I V L$ and $I V D$ that satisfy the cylinder air charge demand, $C A C_{d}$, based on a look-up table. The stored data describe the nominal cylinder air charge and pumping losses as functions of $I V L$ and $I V D$, as shown by the surfaces $\left(S_{c}\right)$ in Figure 13, and $\left(S_{w}\right)$ in Figure 14. For a given $C A C_{d}$ we find the set of $I V L$ and $I V D$ (denoted by $I V L_{f w}$ and $\left.I V D_{f w}\right)$ such that

$$
\begin{array}{r}
S_{c}\left(I V L_{f w}, I V D_{f w}\right)=C A C_{d} \\
\min S_{w}(I V L, I V D)=S_{w}\left(I V L_{f w}, I V D_{f w}\right) .
\end{array}
$$

To illustrate the above mechanism, consider the intersection of the $C A C_{d}$ plane with the $S_{c}$ surface as shown in Figure 13. The curve in the "Valve Lift" and "Valve Duration" plane in Figure 13 shows the selected $I V L^{*}$ and $I V D^{*}$ in response to a command $C A C_{d}=2 \cdot 10^{-4} \mathrm{~kg} /$ event. Figure 14 shows the pumping losses of the nominal experimental engine. The dotted line corresponds to the pumping losses for the particular choices of $I V L^{*}$ and $I V D^{*}$. The feedforward controller selects the particular pair of $\left(I V L_{f w}, I V D_{f w}\right)$ that minimizes pumping losses under a simplified turbulence constraint $\left(I V D_{f w}>110\right.$ degrees). This constraint is based on the same engine combustion stability as in the case with an air throttle and camshaftbased mechanical valvetrain [5].

MEASUREMENTS - The results in [5] combined with the $I V O$ and $I V C$ sensitivity analysis suggest that the optimum intake valve timing corresponds to $I V O=0$ degrees $A T D C$ and $I V C \leq 180$ degrees ATDC. This fact is used in defining the measurements required in the parameter estimation algorithm.

We define the measured cylinder air charge, $C A C_{m}$, 


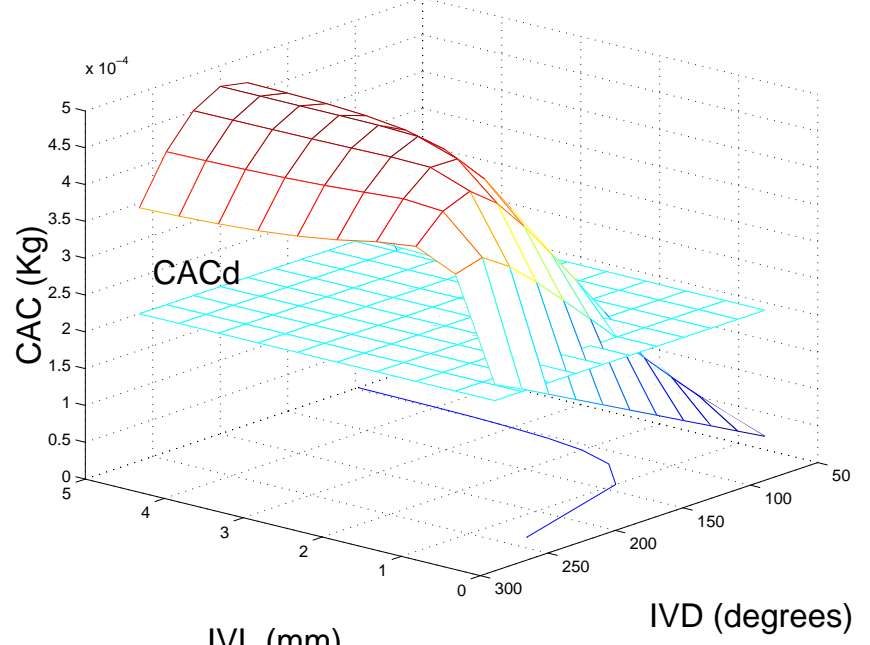

IVL (mm)

Figure 13: Schematic representation of $I V L$ and $I V D$ that satisfy the cylinder air charge demand

as follows

$$
C A C_{m}=\int_{I V O}^{I V O+180} \dot{m}_{\phi}(t) d t
$$

using high sampling rate mass air flow ( $M A F)$ measurements. The second measurement that the developed controller requires is the intake manifold pressure. It is used to calculate the following signal:

$$
I P=\int_{I V O}^{I V O+180} p_{m}(t) d t
$$

Note that the measured signals are delayed by a fundamental event from the inputs to the engine. It can be shown that the measured cylinder air charge, $C A C_{m}$, which is based on the mass air flow through the throttle body contains information about the individual cylinder air charge, $C A C_{a}$.

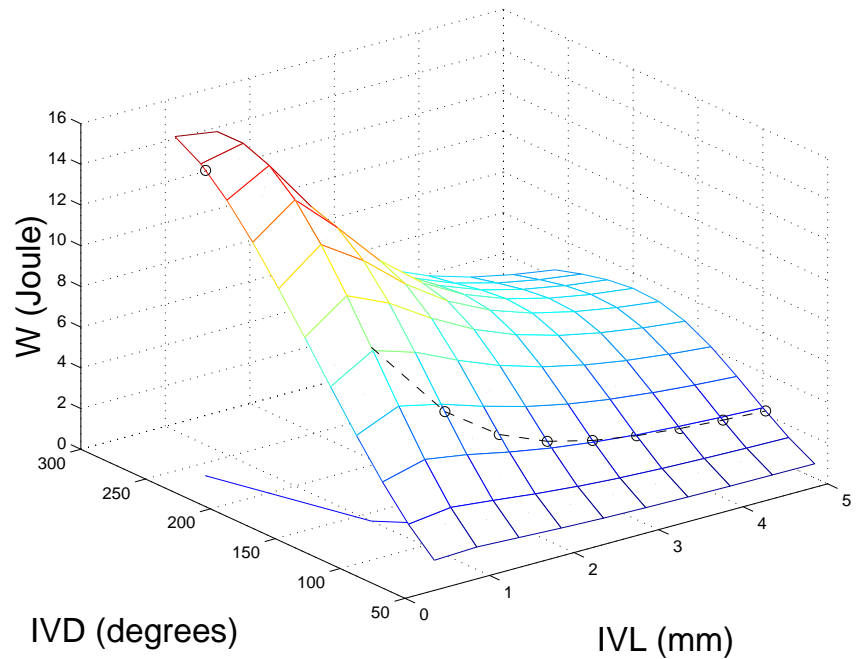

Figure 14: Schematic representation of the minimization algorithm for the pumping losses.

ESTIMATION AND ADAPTATION - The estimation algorithm is needed for the correction of the feedforward controller during modeling error and parameter variation. Sources of variability are:

- Variations in the valve profiles (slopes, opening, closing, seating).

- Changes in the valve effective area due to deposits or wear.

- Design or manufacturing errors.

The empirical data that are used for the engine modeling is a source of model uncertainty. Specifically, the engine controller has to compensate for error in the main throttle effective area, barometric pressure, intake manifold temperature, engine geometric characteristics and engine speed variations. Compensation to engine speed variations is needed because the feedforward map has been developed for a constant engine speed ( $N=1500 \mathrm{rpm})$ to minimize memory requirements.

The parameter estimation in the indirect adaptive controller is based on the plant parameterization. Based on the $I V D$ and $I V L$ sensitivity analysis, we lump all the engine and actuator parameter to two controller parameters:

1. $\xi_{L}$ that scales the intake valve lift, and

2. $\xi_{D}$ that shifts the intake valve duration.

That results in

$$
C A C=f(I V L, I V D)=f^{\circ}\left[\frac{1}{\xi_{L}} I V L,\left(I V D-\xi_{D}\right)\right],
$$

where, $f$ and $f^{\circ}$ is the true and nominal cylinder air charge. Recall here that, $f^{\circ}$ is the nominal cylinder air charge which is computed using the engine model ( $f^{\circ}=S_{c}$ as defined above). Furthermore, the feedforward controller was calibrated based on the nominal cylinder air charge such that $f^{\circ}\left(I V L_{f w}, I V D_{f w}\right)=C A C_{d}$. By sending the feedforward commands ( $I V L_{f w}, I V D_{f w}$ ) to the true engine we measure an error between the measured cylinder air charge $C A C_{m}=f\left(I V L_{f w}, I V D_{f w}\right)$ and the demanded $C A C_{d}=f^{\circ}\left(I V L_{f w}, I V D_{f w}\right)$ because in general $f \neq f^{\circ}$.

The estimation algorithm finds the $\xi_{L}^{*}$ and $\xi_{D}^{*}$ which satisfy the algebraic equation

$$
f^{\circ}\left[\frac{1}{\xi_{L}} I V L_{f w},\left(I V D_{f w}-\xi_{D}\right)\right]-C A C_{m}=0 .
$$

The calculated $\xi_{L}^{*}$ and $\xi_{D}^{*}$ are then used to adapt the feedforward controller by scaling and shifting appropriately its values.

\section{CLOSED LOOP SIMULATION RESULTS}

We now present the simulation results that show cylinder air charge tracking and cylinder balancing under different testing scenarios of engine and actuator conditions. 
We start by presenting the controller tracking capability for unthrottled camless engine that is identical to the one used for the feedforward controller calibration. In this case, the controller is expected to track the desired cylinder air charge within one event (next firing cylinder if the communication and software implementation allow so) since no estimation and adaptation are needed. Figure 15 shows the simulation results for the nominal engine tracking. Indeed it is shown that individual air charge follows the desired cylinder air charge $\left(C A C_{d}\right)$. The corresponding intake valve lift, $I V L_{c}$, and duration, $I V D_{c}$, are shown in subplots 2 and 3 . The four cylinders behave in the same way since they are identical. Engine speed is fixed at 1500 RPM. One can see that perfect tracking is achieved within one event.
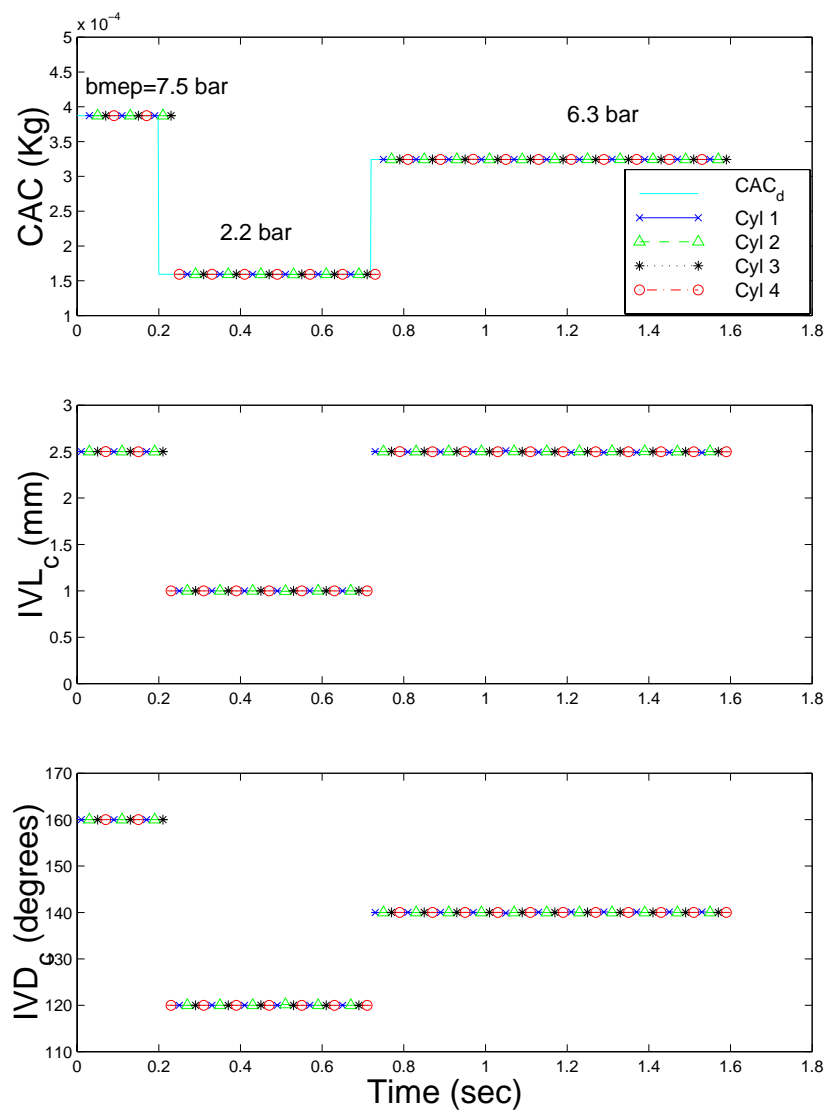

Figure 15: Nominal engine tracking. Each marker represents different cylinder.

In the simulation shown in Figure 16 we alter the nominal engine model by $20 \%$ reduction in the valve effective area of cylinder 1 , and by $10 \%$ reduction in the valve effective area of cylinder 3 . This simulation demonstrates the balancing ability of the developed controller. At time $t=0$ the engine management system requires cylinder air charge equal to $3.9 \cdot 10^{-4} \mathrm{~kg}$ /event (second subplot, dotted line), which corresponds to bmep $=7.5$ bar. The engine speed at that time is $1500 \mathrm{rpm}$ (first subplot). The feedforward controller calculates the neccesary valve lift ( IVL $=2.5 \mathrm{~mm}$, noted by " $\star$ " in third subplot) and duration ( IV D $=160$ degrees, noted by “ $\star$ ” in fourth subplot) for cylinder 1 based on nominal cylinder characteristics. The choice of IVL and IVD results in $3.6 \cdot 10^{-4} \mathrm{~kg} /$ event (second subplot), which correponds to bmep $=7.0$ bar, that is less that the desired cylinder air charge. The true cylinder air charge is estimated using MAP amd MAF measurements. The error between the desired and the estimated cylinder air charge is used in the next induction event of cylinder 1 ( $t=0.08 \mathrm{sec})$ to adapt to $I V L=2.7 \mathrm{~mm}$ and IV $D=164$ degrees. Similarly, the estimator and adaptation rule balance the cylinder air charge for cylinder 3 (noted as "*"). Cylinder 2 and 4 achieve the desired cylinder air charge immediately because they have the nominal (modeled) characteristics that are saved in the feedforward controller.

During the next step at $t=0.2 \mathrm{sec}$, we combine a change in cylinder air charge demand and a change in engine speed. The cylinders achieve the demanded air charge within two cycles (eight firing events). Because of the change in engine speed, the estimation and adaptation schemes are adjusting the feedforward control signals to all cylinders. The control signals $I V L$ and $I V D$ are plotted in subplots 2 and 3. Similar adaptive behavior is shown in the next step of demanded cylinder air charge and engine speed. The controller perfectly balances the air charge to $3.25 \cdot 10^{-4} \mathrm{~kg}$ /event for all cylinders which is the area under the curve shown in Figure 17. The developed control scheme achieves cylinder air charge tracking and balancing even during transient conditions. This scheme will be in future work combined with $A / F$ control.

The simulation shown in Figure 18 is used to test the potential degradation of the adaptive controller performance in the presence of measurement noise. Figure 19 shows the mass air flow signal and the mass air flow measurement with 10:1 signal-to-noise ratio. The simulation engine model was assumed to be equal to the nominal engine model that was used for the calibration of the feedforward controller. The adaptive controller causes the actual cylinder air charge (see Figure 18) to follow the desired cylinder air charge within a small bound. This bound will depend on the controller hardware and software characteristics (word length, numerical integration, etc.) and it will be application specific. Engine testing and further analysis is required to determine the effects of this error in the engine performance.

\section{CONCLUSIONS}

In this paper we developed a phenomenological engine model that can be used to study unthrottled camless engine operation. We assessed the feasibility of air charge control using variable valve motion and conventional engine measurements. We concentrated on engine torque response and pumping losses. We draw the following conclusions:

1. The developed control-oriented engine model agrees reasonably well with the analytical model used in the past by Miller et al. in [5]. 

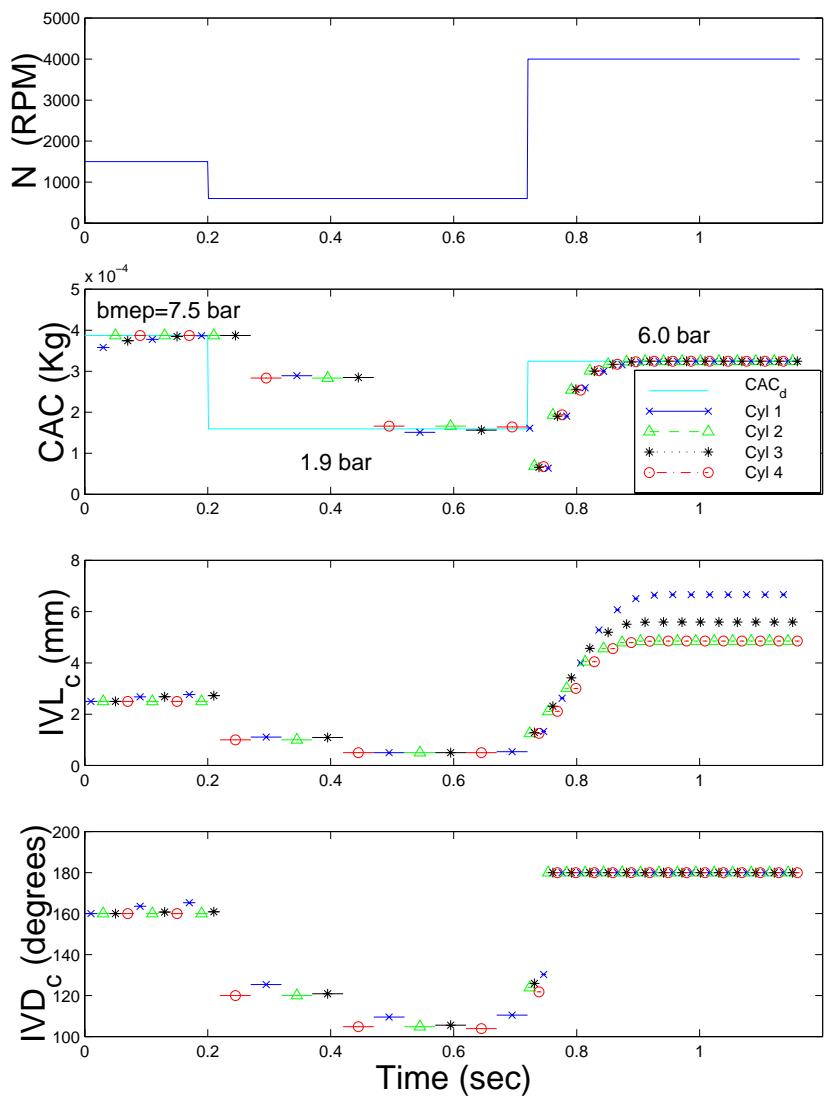

Figure 16: Closed loop response in cylinder air charge and cylinder balancing during fast changes in engine speed and cylinder-to-cylinder variability. Specifically, the engine used for simulation has $20 \%$ and $10 \%$ variation in the effective areas in cylinder 1 and cylinder 3 .

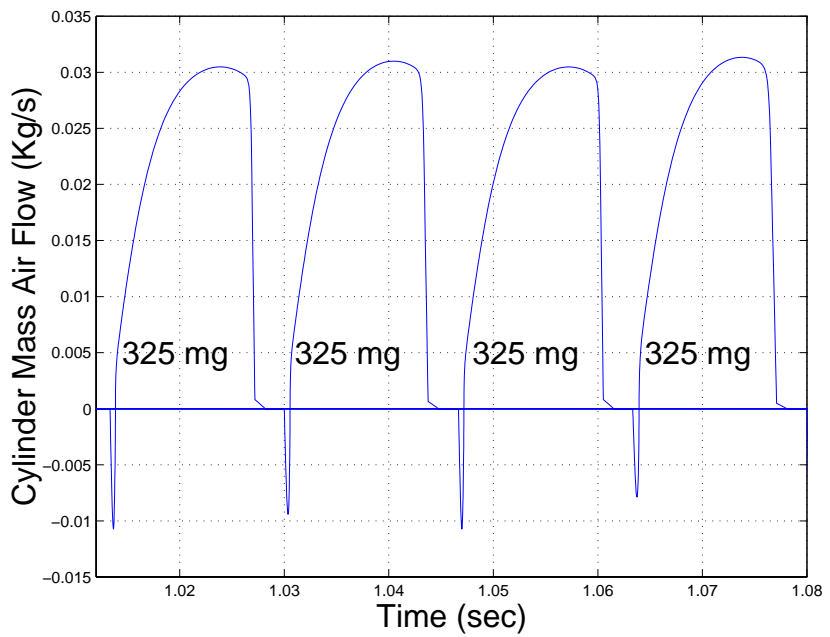

Figure 17: Cylinder mass air flow response demonstrates the cylinder-to-cylinder balancing.
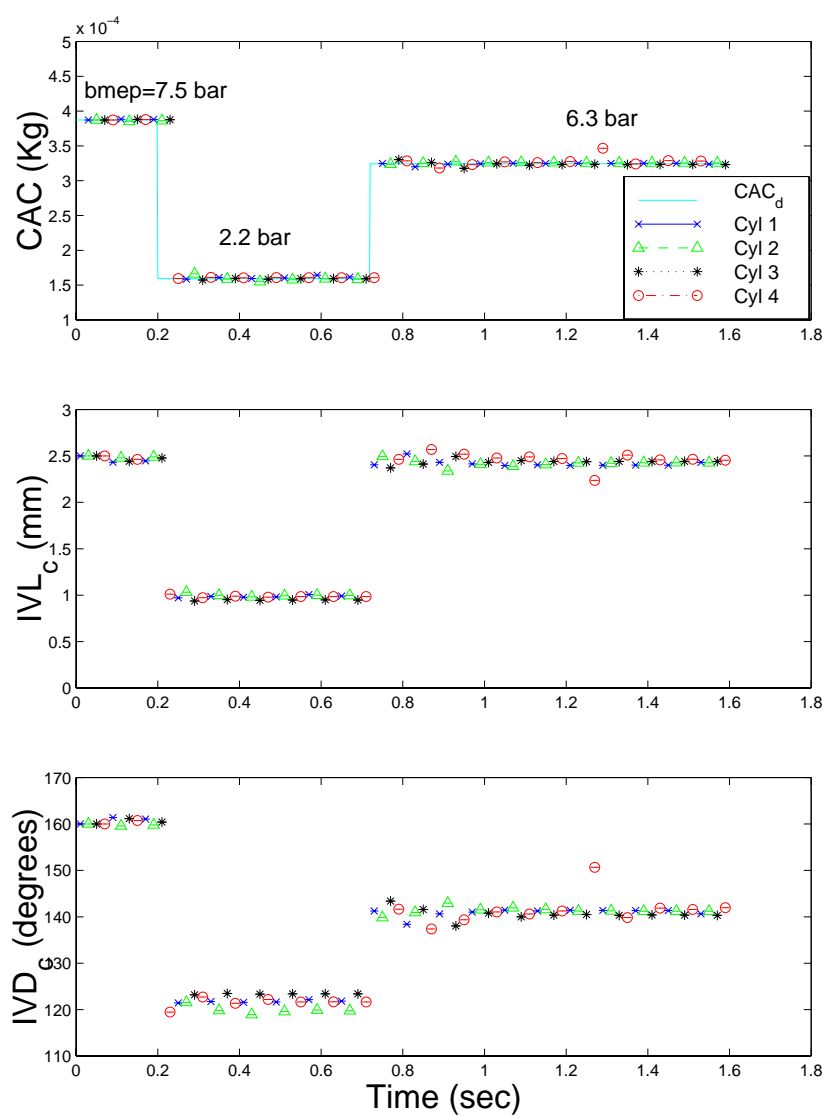

Figure 18: Tracking in the presence of noise.

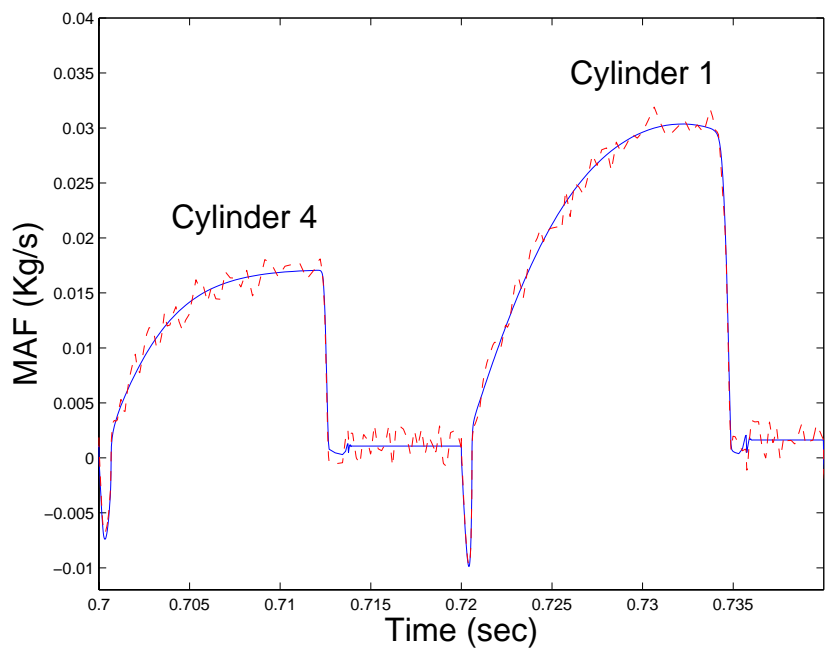

Figure 19: Mass air flow measurements and signal. 
2. A model-based indirect-adaptive controller has been designed that coordinates intake valve lift and intake valve duration to satisfy cylinder charge demands imposed by the driver.

3. The controller consists of a feedforward algorithm, an on-line estimator of parameter variability, and an adaptation scheme.

4. The feedforward controller with adaptive capabilities ensures cylinder-to-cylinder balancing and fast tracking while it minimizes pumping losses.

5. The controller utilizes high sampling rate mass air flow and manifold pressure measurements for estimation and adaptation during component variability and wear.

6. The closed loop performance was tested through simulations on a 4 cylinder 2.0L spark ignited engine.

In future work we plan to extend our estimator and adaptation algorithm to address cylinder and valve overlap for 4-cylinder engines with duration in excess of 180 degrees, as well as six, eight and twelve cylinder engines. We will extend the controller analysis and design to incorporate additional engine performances associated with the exhaust stroke (residual gas fraction, air-to-fuel ratio, etc.). This work will lead to control development encompassing emission, fuel economy and engine torque performance.

\section{ACKNOWLEDGEMENTS}

The authors would like to acknowledge helpful discussions with Mo Haghgooie, Barry Powell, Nizar Trigui, Mary Beth Richards, and Chuck Newman.

\section{REFERENCES}

[1] Ma T. H., 1988, "Effects of Variable Engine Valve Timing on Fuel Economy," SAE Paper No. 880390.

[2] C. Gray, "A Review of Variable Engine Valve Timing," SAE Paper No. 880386, 1988.

[3] P. E. Moraal, J. A. Cook, and J. W. Grizzle, "Modeling the induction process of an automobile engine," Control problems in industry, I. Lasiecka and B. Morton, Ed., Birkhauser, pp. 253-270, 1995.

[4] M. M. Schechter and M. B. Levin, "Camless Engine," SAE Paper No. 960581, 1996.

[5] R. H. Miller, G. C. Davis, C. E. Newman, and M. B. Levin, "Unthrottled Camless Valvetrain Strategy for Saprk-Ignited Engines," Proceedings of the 19th Annual Fall Technical Conference of the ASME Internal Combustion Engine Design Division, Advanced Engine Design, ed. T. Uzkan, ICE-Vol. 29-1, pg.81-94, 1997.
[6] M. Chapman, J. M. Novak, and R. A. Stein, "Numerical Modeling of Inlet and Exhaust Flows in MultiCylinder Internal Combustion Engines," Winter Annual Meeting of the American Society of Mechanical Engineers, Phoenix, AZ, Nov. 1982, in Flows in Internal Combustion Engines, T. Uzkan, Editor.

[7] T. Miyano, M. Hubbard, "Internal Combustion Engine Intake-Maniflod Aspiration Dynamics," Journal of Dynamic Systems, Measurements, and Control, Vol. 112, pg. 596-603, Dec. 1990.

[8] P. R. Crossley and J. A. Cook, "A Nonlinear Model for Drivetrain System Development," IEE Conference 'Control 91', Edinburgh, U.K., March 1991, IEE Conference Publication 332 Vol. 2, pp. 921-925.

[9] J. J. Moskwa and J. K. Hedrick, "Modeling and Validation of Automotive Engines for Control Algorithm Development," ASME J. Dynamic Systems, Meas., and Contr., Vol. 114, pp. 278-285, 1992.

[10] J. B. Heywood, Internal Combustion Engine Fundamentals, McGraw-Hill, 1988.

[11] J. M. Novak, "Simulation of the Breathing Process and Air-Fuel Ratio Distribution Characteristics of Three-Valve, Stratified Charge Engines," SAE Paper No. 770881, 1977.

[12] B. K. Powell, "Real Time Integration of Orifice Mass Flow Rate Equations," Applied Dynamics International Users Society, Norfolk, Virgina, June 12, 1988.

[13] L. F. Shampine and C. W. Gear, "A User's View of Solving Stiff Differential Equations," SIAM Review, Vol. 21, No 1, pg. 1-17, January 1979.

[14] Karl Astrom and Bjorn Wittenmark, Adaptive Control, Addison Wesley, 1989.

[15] P. A. Ioannou and J. Sun, Robust Adaptive Control, Prentice Hall, 1996. 